No. $1999 / 08$

Nominal Rigidities and the

Optimal Rate of Inflation

Torben M. Andersen 


\title{
Nominal Rigidities and the Optimal Rate of Inflation*
}

\author{
Torben M. Andersen*
}

November 1998

\begin{abstract}
This paper analyses two reasons why inflation may interfere with price adjustment so as to create inefficiencies in resource allocation at low rates of inflation. The first argument is that the higher the rate of inflation the lower the likelihood that downward nominal rigidities are binding (the Tobin argument) which implies a non-linear Phillips-curve. The second argument is that low inflation strengthens nominal price rigidities and thus impairs the flexibility of the price system resulting in a less efficient resource allocation. It is argued that inflation can be too low from a welfare point of view due to the presence of nominal rigidities, but the quantitative importance is an open question.
\end{abstract}

Keywords: Nominal rigidities, allocative efficiency, optimal rate of inflation

JEL classification: E20, E30

* Paper prepared for the conference "Implementation of Price Stability”, Frankfurt, September 1998. Comments and suggestions from conference participants and in particular the discussants Roel Beetsma and Axel Weber are gratefully acknowledged.

** Department of Economics, University of Aarhus, DK-8000 Aarhus C, Denmark, E-mail: tandersen@econ.au.dk 


\section{Introduction}

Many countries have been through a disinflationary process and have now credibly established a low and stable rate of inflation. This has accentuated the question of the appropriate level at which inflation should be stabilized. Is the optimal rate of inflation zero or are there strong arguments that a slight positive rate of inflation - say 2-3\% - is optimal?

In addressing the question of the optimal rate of - anticipated - inflation, the focus has primarily been on the inflation tax on money holdings (see eg Chadka et al (1998) for a recent discussion). According to this argument, welfare considerations calls for a negative rate of inflation to ensure a zero nominal rate of interest. However, putting the inflation tax in a $2^{\text {nd }}$ best setting with other distortionary taxes in general implies that this tax should be used and thus inflation should be positive ${ }^{1}$.

Another argument is that money is not in general super-neutral. Changes in the inflation rate can via various mechanisms affect the allocation of resources. While there is a strong theoretical case for the absence of super-neutrality, it is widely agreed that the quantitative importance of this is very modest. This is also reflected in numerous empirical studies attempting to identify a relationship between inflation and growth, but for moderate rates of inflation no such relation has been established, see eg Gylfason and Herbertsson (1998).

These traditional mechanisms do not capture the problems raised in policy debate, namely that a too low rate of inflation may be an impediment to the functioning of the market mechanism and thus cause misallocation possibly in the form of higher unemployment. This popular view does not square well with mainstream economic theory which has a central result that the rate of unemployment is independent of the (anticipated) rate of inflation. The quest for disinflationary policies have also been based on this insight, namely, that if high inflation does not buy a lower rate of unemployment, it can be eliminated costlessly at least in the long run.

The layman's view on inflation thus seems to be based on the assertion that there at least is a Phillips-curve trade-off at low rates of inflation. The purpose of this paper analyse why the presence of nominal rigidities have implications for the optimal rate of inflation, and why there is a case for arguing that the rate of inflation can be too low. At first sight it may seem that nominal rigidities and the optimal rate of inflation are separate issues as long as we stick to the maintained hypothesis that nominal shocks do not have any real effect in the long run (Classical

\footnotetext{
${ }^{1}$ Feldstein (1996) argues that these effects are dominated by inflationary distortions in the taxation system, in particular between inflation and capital income taxation.
} 
neutrality prevails in the long-run). Nominal rigidities may play an important role in the short run, but not in the long run. Accordingly, they should be inconsequential to the structural aspects of relevance for the determination of the optimal rate of inflation.

The following presents and discusses two arguments why nominal rigidities have implications for the optimal rate of inflation. The first argument is based on the assertion that zero is a magic number for nominal adjustments. While upward adjustments(increases) are unproblematic, there is strong resentment to downward adjustments(decreases) in nominal wages and/or prices. If such asymmetries prevail widely in nominal wage and price adjustment, it follows that the market system performs poorly with less efficiency at low rates of inflation, and that the optimal rate of inflation is positive.

The second argument takes as its starting point that price and wage adjustments are essential to attain efficiency in resource allocation and that nominal rigidities arise endogenously. Since wage and price decisions in a decentralized market economy are the responsibility of well defined agents pursuing well defined objectives there may be a problem to the extent that the private incentives to adjust price are insufficient. This may arise if say adjustment entails explicit or implicit costs. However, by its choice of the rate of inflation the authorities can affect the incentives of wage and price setting agents - the larger the rate of inflation the larger the incentive to adjust nominal wages and prices. It follows that a positive rate of inflation can induce more wage/price flexibility and thereby contribute to a more efficient resource allocation.

This paper sets up two stylized models to present the mechanisms underlying these two arguments, and discusses their strength from both a theoretical and an empirical perspective. The paper is organized as follows: section 2 discusses the interplay between inflation and downward nominal rigidities, while section 3 addresses the relation between inflation, endogenous price rigidities, and efficiency in resource allocation. Section 4 provides a short summary of the empirical evidence on nominal rigidities, and section 5 discusses the policy implications.

\section{Downward Nominal Rigidities}

An often made argument is that inflation works as grease facilitating adjustment in the presence of downward rigidities in nominal wages or prices. The argument is that various sectoral shocks continously require adjustment of relative prices, some have to increase and others to decrease. The adjustment process goes through nominal wage and price adjustment. Hence, some nominal prices (wage) will have to fall, and other to rise to ensure the proper adjustment of relative prices. If the underlying rate of inflation is high, the required adjustment of relative prices is ensured even if all nominal prices (wages) rise by having some to raise more than 
others. However, with a low rate of inflation the adjustment process may require downward adjustment of some nominal prices (wages). To the extent that there are downward nominal rigidities, the adjustment process may be strained.

This idea is informally developed in the seminal paper by Tobin (1972) in which he contends that:

Higher prices or faster inflation can diminish involuntary, disequilibrium unemployment, even though voluntary, equilibrium labour supply is entirely free of money illusion (Tobin, 1972, p 2).

Tobin's story of inflation as grease was based on a setting with continuous sectoral reallocations ("stochastic macroeconomic equilibrium") and thus a need for adjustment of relative prices. It was argued that inflation may grease the adjustment process to the extent that there are downward nominal wage rigidities. While this idea has since been rather popular and often encountered in policy debates (see eg Edey (1995)), it has surprisingly not received much attention in the theoretical literature. One exception is the recent paper by Akerlof et al (1996) which embodies the idea in a dynamic model. The structure of the model is, however, so complicated that analytical solutions are not available, and the authors take resort to simulations to illustrate that downward nominal rigidities may produce a non-linear Phillips- curve.

To develop this idea in more detail let us set up a stylized model with sectoral reallocations ${ }^{2}$. Specifically we consider a labour market example, but a product market example could easily be developed along the same lines.

Consider an economy with a continuum of separate (geographically) labour markets indexed by $\mathbf{j} \in \mathrm{J}$ and no mobility of labour. Labour demand in a given market $\mathrm{j}$ is (in logs)

$$
1_{j}^{d}=\alpha_{0}+\alpha_{1}\left(p-w_{j}\right)+u_{j}
$$

where $\mathrm{p}$ is the price level (all firms supply to the same output market), and $\mathrm{u}_{\mathrm{j}}$ is a shock to labour demand. The shock variable can have both an economy-wide component $(u)$ and a sector

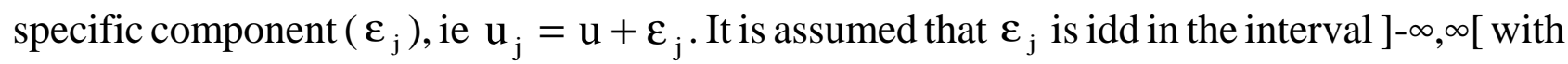
a symmetric density function $\mathrm{h}\left(\varepsilon_{\mathrm{j}}\right)$. It is moreover assumed that

\footnotetext{
2 This is related to the sectoral shift model of business cycles, cf. e.g. Lilien(1982).
} 


$$
\int_{-\infty}^{\infty} \varepsilon^{j} h\left(\varepsilon^{j}\right) d j=0
$$

that is, the $\varepsilon$ 's represent pure sectoral shocks with no direct aggregate consequence.

Labour supply in market $\mathrm{j}$ reads

$$
1_{\mathrm{j}}^{\mathrm{s}}=\beta_{0}+\beta_{1}\left(\mathrm{w}_{\mathrm{j}}-\mathrm{p}\right)
$$

If nominal wages are flexible and adjust to as to ensure market clearing, it follows that the equilibrium wage is given as

$$
\mathrm{w}_{\mathrm{j}}^{*}=\frac{\alpha_{0}+\beta_{0}}{\alpha_{1}+\beta_{1}}+\mathrm{p}+\frac{1}{\alpha_{1}+\beta_{1}} \mathrm{u}_{\mathrm{j}}
$$

and employment is

$$
1_{\mathrm{j}}^{*}=\overline{\mathrm{l}}+\frac{\beta_{1}}{\alpha_{1}+\beta_{1}} \mathrm{u}_{\mathrm{j}} \quad ; \overline{\mathrm{l}} \equiv \beta_{0}+\beta_{1}\left(\frac{\alpha_{0}+\beta_{0}}{\alpha_{1}+\beta_{1}}\right)
$$

Aggregating over labour markets, we find that total employment can be written

$$
1^{*}=\int_{j} 1_{j}^{*} h\left(\varepsilon_{j}\right) d j=\bar{l}+\frac{\beta_{1}}{\alpha_{1}+\beta_{1}} u
$$

In case of flexible prices and wages the adjustment process ensures that aggregate employment is affected only by aggregate shocks. The sectoral shocks are absorbed by adjustment of relative prices.

Consider now the adjustment process in case of a downward nominal wage rigidity, ie assume that the nominal wage in market $\mathrm{j}$ is determined as

$$
\mathrm{w}_{\mathrm{j}}=\max \left\{\mathrm{w}_{\mathrm{j}}(-1), \mathrm{w}_{\mathrm{j}}^{*}\right\}
$$

where $\mathrm{w}_{\mathrm{j}}(-1)$ is the nominal wage in market $\mathrm{j}$ in the previous period. This wage-setting rule implies that nominal wages can never fall, but they will raise to the market clearing level provided it is larger than the past nominal wage.

Assume that employment is demand determined. It follows that

$$
1_{\mathrm{j}}=\alpha_{0}+\alpha_{1}\left(\mathrm{p}-\max \left(\mathrm{w}_{\mathrm{j}}(-1), \mathrm{w}_{\mathrm{j}}^{*}\right)\right)+\mathrm{u}_{\mathrm{j}}
$$

Defining 


$$
\begin{aligned}
& \pi \equiv \mathrm{p}-\mathrm{p}(-1) \\
& \widetilde{\mathrm{w}}_{\mathrm{j}}(-1)=\mathrm{w}_{\mathrm{j}}(-1)-\mathrm{p}(-1)
\end{aligned}
$$

Employment in market $\mathrm{j}$ can be written

$$
1_{j}=\alpha_{0}+\alpha_{1}\left(\pi-\max \left(\widetilde{w}_{j}(-1), \pi+\frac{1}{\alpha+\beta} u_{j}\right)\right)+u_{j}
$$

Define $\widetilde{\mathrm{u}}_{\mathrm{j}}$ as the critical value of the shock to labour demand in market $\mathrm{j}$ for which the past wage equals the market clearing wage, ie

$$
\widetilde{\mathrm{w}}_{\mathrm{j}}(-1) \equiv \pi+\frac{1}{\alpha+\beta} \widetilde{\mathrm{u}}_{\mathrm{j}}
$$

Hence,

$$
1_{j}= \begin{cases}\frac{\beta_{1}}{\alpha_{1}+\beta_{1}} u_{j} & \text { for } u_{j} \geq \widetilde{u}_{j} \\ \alpha_{1}\left(\pi-\widetilde{w}_{j}(-1)+u_{j}\right. & \text { for } u_{j}<\widetilde{u}_{j}\end{cases}
$$

For sectors experiencing sufficiently large shocks $\left(\mathrm{u}_{\mathrm{j}} \geq \widetilde{\mathrm{u}}_{\mathrm{j}}\right)$ employment is at the market clearing level, while it for other sectors $\left(\mathrm{u}_{\mathrm{j}}<\mathrm{u}_{\mathrm{j}}\right)$ is lower due to the failure of wages to adjust in the downward direction.

Aggregate employment can now be written

$$
\begin{aligned}
l= & \int_{-\infty}^{\widetilde{u}_{j}}\left(\alpha_{1}\left(\pi-\widetilde{\mathrm{w}}_{j}(-1)\right)+\mathrm{u}+\varepsilon^{\mathrm{j}}\right) \mathrm{h}\left(\varepsilon^{\mathrm{j}}\right) \mathrm{dj} \\
& +\int_{\widetilde{\mathrm{u}}_{\mathrm{j}}}^{\infty} \frac{\beta_{1}}{\alpha_{1}+\beta_{1}}\left(\mathrm{u}+\varepsilon^{\mathrm{j}}\right) \mathrm{h}\left(\varepsilon^{\mathrm{j}}\right) \mathrm{dj}
\end{aligned}
$$

It follows straightforwardly that

$$
1 \leq 1^{*}
$$

that is, the downward nominal wage rigidity causes aggregate employment to be lower than if 
the nominal wage could be adjusted flexibly. The reason is that the sectors facing a fall in labour demand calling for a nominal wage reduction are constrained by the downward rigidity of wages. Accordingly, wages do not fall enough to moderate the employment effects of the negative sectoral shocks. The wage rigidity therefore implies that sectoral shocks effect aggregate employment.

The effect of inflation on employment is found to be

$$
\begin{aligned}
\frac{\partial \mathrm{l}}{\partial \pi} & =\alpha_{1} \int_{-\infty}^{\tilde{u}} \mathrm{~h}\left(\varepsilon_{\mathrm{j}}\right) \mathrm{dj} \\
& =\alpha_{1} \phi>0
\end{aligned}
$$

where

$$
\phi \equiv \int_{-\infty}^{\widetilde{u}_{j}} \mathrm{~h}\left(\varepsilon_{\mathrm{j}}\right) \mathrm{dj}
$$

is the probability that a given sector is constrained by a downward rigid nominal wage or equivalently the fraction of sectors in the economy constrained by downward wage rigidity.

Inflation increases employment since higher inflation loosens the constraint implied by the downward rigidity of nominal wages. However, the effect is decreasing in the inflation rate, ie

$$
\frac{\partial^{2} 1}{\partial \pi^{2}}=\alpha h\left(\widetilde{\mathrm{u}}_{\mathrm{j}}\right) \frac{\partial \widetilde{\mathrm{u}}_{\mathrm{j}}}{\partial \pi}<0
$$

This also brings out that essential to evaluate the quantitative importance of this effect is the prevalence of downward rigidities in the economy. In section 4 empirical evidence on downward rigidities is discussed.

Figure 1 depicts the non-linear relation between inflation and employment implied by downward nominal wage rigidity 
Fig. 1. Phillips-curve - Downward Rigidity of Nominal Wages.

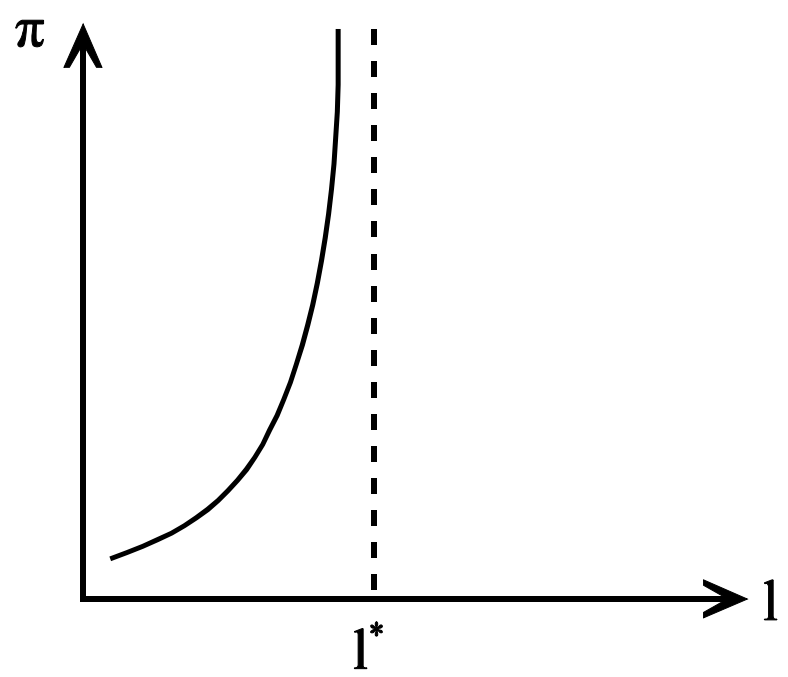

Notice that the downward nominal wage rigidity also has implications for how aggregate (real) shocks affect employment. It follows straightforward that with binding downward rigidities an aggregate real shock has a larger employment effects as compared to the case with fully flexible wages, ie

$$
\frac{\partial l}{\partial u}=\int_{-\infty}^{\widetilde{u}_{j}} h\left(\varepsilon_{j}\right) d j+\frac{\beta_{1}}{\alpha_{1}+\beta_{1}} \int_{\widetilde{u}_{j}}^{\infty} h\left(\varepsilon_{j}\right) d j>\frac{\beta_{1}}{\alpha_{1}+\beta_{1}}=\frac{\partial 1^{*}}{\partial u}
$$

The reason being that sectors constrained by the downward wage rigidity do not experience the same wage rise as non constrained sector when exposed to the aggregate real shock, hence employment expands more with a binding downward wage rigidity.

Note also that inflation lowers the fraction of constrained firms

$$
\frac{\partial \phi}{\partial \pi}<0
$$

as do aggregate shocks to employment

$$
\frac{\partial \phi}{\partial \mathrm{u}}<0
$$

that is, the higher the inflation rate and the underlying economy-wide change in labour demand (productivity), the lower the possibility that downward nominal wage rigidity constrains the adjustment mechanism.

While the model is not explicitly designed for welfare evaluations, it follows straightforwardly that if the allocation under flexible wages is used as the bench-mark case then downward nomi- 
nal wage rigidities cause a welfare loss by reducing aggregate employment. It also follows that the consequences of downward rigidities and thus the welfare loss can be reduced by increasing the rate of inflation. However, the effects are non-linear. An increase in inflation has a larger effect on employment if the initial situation is characterized by a low rate of inflation rather than a high rate of inflation.

The argument developed here relies on the presence of downward nominal rigidities. Is there theoretical support of this hypothesis?

One argument is that inflation tends to produce downward nominal rigidities ${ }^{3}$. To see this, consider a monopolist charging nominal prices subject to menu costs in an inflationary environment. As is well-known from menu-cost models, the optimal policy for the firm is to follow a $(\mathrm{s}, \mathrm{S})$-type policy such that the nominal price is set so as to ensure a relative price $\mathrm{s}$ each time the price is reset, and when the relative price has been eroded to $\mathrm{S}$ by inflation, then a nominal price change is called for.

The fact that inflation automatically erodes the relative price for firms quoting nominal prices has important implications for how firms adjust their prices. Firms who after a change in market conditions find that they have a too high relative price will be inclined not to lower their nominal price since inflation automatically and costlessly reduces their relative price, while firms which have a too low relative price will adjust their price immediately. Inflation thus causes a form of downward rigidity in the adjustment of nominal prices - prices tend to be adjusted more in the upward and than in the downward direction (See Tsiddon (1991)).

This means that downward rigidity is less likely to prevail when inflation is lowered. A policy of low and stable inflation will thus create an environment in which downward rigidities prevail less frequently. This is a serious criticism of the argument that downward nominal rigidities constrain the adjustment process at low rates of inflation. Of course, there are different ways to justify downward rigidities, but still this point questions the extent to which behaviour will change to radical changes in the level of inflation so as to eliminate the problem.

Nominal rigidities may also arise for strategic reasons in the bargaining game between employers and employees (Holden, 1994; 1997). In case of disagreement it does not necessarily follow that there is an open labour market conflict. Instead, the common practice is almost

3 Downward rigidities of relative prices can arise due to inventories, information problems or strategic reasons, see Andersen (1994). 
everywhere that production continues with the same money wage as in the old contract until a new agreement is settled. This "hold-out" option may follow from legal rules or arise as a social convention. This "hold-out" option may result in nominal wage rigidity since in the case of a moderate change in nominal demand relative to the earlier wage, it will pay neither for unions nor for employers to initiate a labour market conflict to change the wage (Holden (1994)). In general the theory leaves open whether wages become upward or downward rigid. A bias towards downward stickiness arises if workers have larger possibilities than employers of inflicting damage on the other party during a hold-out (by working-to-rule or reducing effort in other ways).

\section{Endogenous Price Rigidity}

A shortcoming of the preceding analysis is that downward nominal rigidities are postulated and it is thereby disregarded that the possibility that the incentives underlying price and wage adjustment may be affected by policy changes like changes in the rate of inflation. It is therefore natural to turn to models which generate nominal rigidities endogenously. There is by now a rich variety of models generating nominal rigidities featuring adjustment costs, information problems, synchronization issues and strategic interactions, cf e.g. Andersen (1994)). Since models based on adjustment costs (menu cost models) are the most easy to handle we shall use this as a work horse to explore the implications of inflation for price adjustment and resource allocation. The specific example considered here involves nominal price adjustments but an argument along the same lines could be developed for nominal wage adjustment.

If price changes are costly it follows that the incentive to change prices depends on the changes in market conditions. The higher the rate of inflation, other things being equal, the larger the incentive to change nominal prices to maintain the optimal relative price and vice versa. This suggests that nominal prices are more flexible at higher rates of inflation and therefore that the price mechanism works better as a resource allocation mechanism for higher rates of inflation. At very low rates of inflation the incentive to change prices is reduced and this may interfere with the need to change prices to attain an efficient resource allocation. To explore this idea consider the following stylized model.

Assume an economy with a continuum of monopolistic firms that produce differentiated nonstorable products. Firms indexed by i, are uniformly distributed on the unit interval and have a measure of 1 . The representative consumer has a demand function defined over the commodities given as

$$
x_{i}=f\left(p_{i}\right) \quad f^{\prime}<0
$$


where $p_{i}$ is the relative price charged for commodity $\mathrm{i}$.

The firm produces subject to a production function

$$
\mathrm{y}_{\mathrm{i}}=\frac{1}{\mathrm{k}_{\mathrm{i}}} \mathrm{l}_{\mathrm{i}} \quad \mathrm{k}_{\mathrm{i}}>0
$$

where $\mathrm{k}_{\mathrm{i}}$ is an exogenous productivity parameter and $\mathrm{l}_{\mathrm{i}}$ is labour input. Real profit can be written

$$
V=\left(\frac{P_{i}}{M}-k_{i} \frac{W}{M}\right) f\left(\frac{P_{i}}{M}\right)
$$

Assuming that nominal wages are proportional to the money stock $((\mathrm{W} / \mathrm{M})=$ constant normalized to unity for convenience ) to rule out that the argument relies on an imposed nominal wage rigidity we find that real profit to firm $i$ charging a nominal price $P_{i}$ and having marginal real costs $\mathrm{k}_{\mathrm{i}}$ can be written

$$
\mathrm{V}\left(\frac{\mathrm{P}_{\mathrm{i}}}{\mathrm{M}}, \mathrm{k}_{\mathrm{i}}\right)=\left(\frac{\mathrm{P}_{\mathrm{i}}}{\mathrm{M}}-\mathrm{k}_{\mathrm{i}}\right) \mathrm{f}\left(\frac{\mathrm{P}_{\mathrm{i}}}{\mathrm{M}}\right)
$$

Specifically, it is assumed that marginal real costs of production are given as

$$
\mathrm{k}_{\mathrm{i}}=1+\varepsilon_{\mathrm{i}}
$$

where $\varepsilon_{\mathrm{i}}$ has a density function $\left(\mathrm{h}\left(\varepsilon_{\mathrm{i}}\right)\right)$ which is symmetric around zero and with support in $[\underline{\varepsilon}, \bar{\varepsilon}]$, where $\underline{\varepsilon}>0$.

The shock to the marginal costs of production is a real shock creating a need for adjustment of relative prices. This interacts with the need for nominal price adjustment created by inflation.

The optimal price for firm $\mathrm{i}$ is readily found to be

$$
\mathrm{P}_{\mathrm{i}}^{*}=\mathrm{mk}_{\mathrm{i}} \mathrm{M}, \mathrm{m} \equiv\left(1-\frac{1}{\eta}\right)^{-1}>1
$$

where $\eta$ is the elasticity of demand.

Assume that the initial nominal price of the firm is $\overline{\mathrm{P}}_{\mathrm{i}}(\equiv \mathrm{m} \overline{\mathrm{M}})$ and that there is a fixed real cost of adjusting the price (c). The firm has thus to weight the cost of having an inoptimal nominal price relative to the cost of adjusting the price. Proceeding with the usual method adopted in the menu-cost literature, we use that 


$$
\begin{aligned}
\mathrm{V}\left(\frac{\mathrm{P}_{\mathrm{i}}}{\mathrm{M}}, \mathrm{k}_{\mathrm{i}}\right) & =\mathrm{V}\left(\frac{\mathrm{P}_{\mathrm{i}}^{*}}{\mathrm{M}}, \mathrm{k}_{\mathrm{i}}\right)+\mathrm{V}_{\frac{\mathrm{P}_{\mathrm{i}}}{\mathrm{M}}}\left(\frac{\mathrm{P}_{\mathrm{i}}^{*}}{\mathrm{M}}\right)\left(\frac{\mathrm{P}_{\mathrm{i}}}{\mathrm{M}}-\frac{\mathrm{P}_{\mathrm{i}}^{*}}{\mathrm{M}}\right) \\
& +\frac{1}{2} \mathrm{~V}_{\frac{\mathrm{P}_{i}}{\mathrm{M}}}^{\prime \prime}\left(\frac{\mathrm{P}_{\mathrm{i}}^{*}}{\mathrm{M}}\right)\left(\frac{\mathrm{P}_{\mathrm{i}}}{\mathrm{M}}-\frac{\mathrm{P}_{\mathrm{i}}^{*}}{\mathrm{M}}\right)^{2}
\end{aligned}
$$

Since by definition $\mathrm{V}_{\frac{\mathrm{P}_{\mathrm{i}}}{\mathrm{M}}}\left(\frac{\mathrm{P}_{\mathrm{i}}^{*}}{\mathrm{M}}\right)=0$, it follows that the profit loss from maintaining the old (inoptimal) nominal price is given as

$$
\mathrm{V}\left(\frac{\mathrm{P}_{\mathrm{i}}^{*}}{\mathrm{M}}, \mathrm{k}_{\mathrm{i}}\right)-\mathrm{V}\left(\frac{\overline{\mathrm{P}}_{\mathrm{i}}}{\mathrm{M}}, \mathrm{k}_{\mathrm{i}}\right)=\phi\left(\frac{\overline{\mathrm{P}}_{\mathrm{i}}}{\mathrm{M}}-\frac{\mathrm{P}_{\mathrm{i}}^{*}}{\mathrm{M}}\right)^{2}
$$

where

$$
\phi \equiv-\frac{1}{2} \mathrm{~V}_{\frac{\mathrm{P}_{\mathrm{i}}}{\mathrm{M}}}^{\prime \prime}\left(\frac{\mathrm{P}_{\mathrm{i}}^{*}}{\mathrm{M}}\right)>0
$$

It follows straightforward that the firm decides not to change its price if

$$
\left(\frac{\overline{\mathrm{P}}_{\mathrm{i}}}{\mathrm{M}}-\frac{\mathrm{P}_{\mathrm{i}}^{*}}{\mathrm{M}}\right)^{2}<\frac{\mathrm{c}}{\phi}
$$

Assume that $\mathrm{M} \equiv(1+\pi) \overline{\mathrm{M}}$ and use the approximation $(1+\mathrm{x})^{-1} \cong 1-\mathrm{x}$, it follows that the firm keeps an unchanged price if

$$
\left(\pi+\varepsilon_{\mathrm{i}}\right)^{2}<\frac{\mathrm{c}}{\phi \mathrm{m}^{2}} \equiv \tau
$$

This implies that the firm maintains its initial nominal price if the shock to marginal cost lies in the interval

$$
-(\pi+\tau)<\varepsilon_{\mathrm{i}}<\tau-\pi
$$

The price policy of the firm is seen to depend on the rate of inflation $(\pi)$.

The probability that a given firm keeps a fixed price is given as

$$
\psi \equiv \int_{-(\pi+\tau)}^{\tau-\pi} h\left(\varepsilon_{\mathrm{i}}\right) \mathrm{di}
$$


By assumption this is the fraction of firms not changing their price.

It is easily shown that inflation is inducing price flexibility as

$$
\frac{\partial \psi}{\partial \pi}=-h(\tau-\pi)+h(-(\tau+\pi)) \leq 0 \text { for } \pi \geq 0
$$

that is, the higher the rate of inflation, the smaller the fraction of firms keeping unchanged nominal prices. The intuition for this result is that if inflation is low, the need to adjust prices is lower and this produces nominal price rigidities. This implies not only that nominal shocks have real effects, but also that the adjustment to real shocks (here the $\varepsilon_{\mathrm{i}}$ 's) is impaired.

Considering how price rigidity affects relative prices we have

$$
\frac{\overline{\mathrm{P}}_{\mathrm{i}} / \mathrm{M}}{\mathrm{P}_{\mathrm{i}}^{*} / \mathrm{M}}=\frac{1}{(1+\pi)\left(1+\varepsilon_{\mathrm{i}}\right)}
$$

It follows that inflation tends to imply that the firms who do not adjust their price tend to have a "too low" price. The real shock implies that firms with high (low) marginal costs tend to have a too low (high) price.

Turning to the interval supporting an unchanged price $[-(\tau+\pi), \tau-\pi]$, we find that it is only symmetric around zero in the case of an underlying nominal growth rate of zero $(\pi=0)$. If nominal growth is positive, it will be negatively biased, that is, unchanged prices tend to prevail for firms experiencing low marginal costs (low $\varepsilon_{\mathrm{i}}$ ) and they therefore tend to have a too high price. This gives an asymmetry or downward rigidity such that the higher the rate of inflation, the more prices are downward rigid, cf the discussion in section 2 . That is, the interval supporting fixed prices moves "leftwards" when inflation increases. This means that unchanged prices tend to prevail for firms for which the optimal price policy calls for a price decrease.

This analysis suggests that the choice of the optimal rate of inflation is not trivial. Higher inflation necessitates price adjustments which are good for resource allocation, but entails adjustment costs. On the other hand, low inflation implies price rigidities, and low adjustment costs, but an inadequate adjustment to real shocks. There is a trade-off between the costs of price changes and the efficiency of the price system in allocating resources.

A welfare evaluation is complicated in the present setting by the market imperfections caused by the market power of price-setting firms. This does in itself create a welfare loss relative to the case of competitive firms. This is reflected in the mark-up parameter $\left(\mathrm{m}^{*}\right)$. Since this is 
unaffected by inflation, we use the case of fully flexible prices as the benchmark for the welfare considerations. To assess the welfare consequences of inflation, we thus adopt a $2^{\text {nd }}$ best approach in the sense that market imperfections imbedded in the market power of firms is taken as given. It is thus asked what rate of inflation maximizes the welfare of consumers taken as given the market power of firms (constrained efficiency), see appendix.

The misallocation of resources caused by price rigidity can be written (see appendix)

$$
\mathrm{A}(\pi)=\chi \int_{-(\tau+\pi)}^{\tau-\pi}\left(\pi+\varepsilon_{\mathrm{i}}\right)^{2} h\left(\varepsilon_{\mathrm{i}}\right) \mathrm{d} \varepsilon_{\mathrm{i}}
$$

We have that

$$
\begin{aligned}
& \frac{\partial \mathrm{A}(\pi)}{\partial \pi}=\chi \tau^{2}[\mathrm{~h}(-(\tau+\pi))-\mathrm{h}(\tau-\pi)] \\
& +\chi \int_{-(\tau+\pi)}^{\tau-\pi} 2\left(\pi+\varepsilon_{\mathrm{i}}\right) \mathrm{h}\left(\varepsilon_{\mathrm{i}}\right) \mathrm{d} \varepsilon_{\mathrm{i}} \geq 0
\end{aligned}
$$

The effects of inflation on the misallocation of resources thus involves two effects. First, higher inflation reduces the fraction of firms keeping a rigid price by moving the interval supporting rigid prices leftward. Second, the higher the inflation rate, the larger the discrepancy between the optimal and the rigid price and thus resource misallocation for those firms not changing their prices.

In the appendix it is shown that there exists a rate of inflation $\hat{\pi}>0$ such that

$$
\mathrm{A}(\hat{\pi})<\mathrm{A}(\mathrm{O})
$$

that is, there are efficiency gains in terms of a better allocation of resources to be reaped by choosing a strictly positive rate of inflation.

In general, there is not a monotone relation between inflation and misallocation of resources due to the two counteracting effects mentioned above. However, it can be shown (see appendix) that

$$
\lim _{\pi \rightarrow \infty} \mathrm{A}(\pi)=0
$$

ie at very high rates of inflation nominal prices are fully flexible and hence price rigidity is not a source of misallocation of resources. 
From this one may infer that very high rates of inflation are optimal as they eliminate the distortions caused by nominal rigidities. Such a conclusion disregards the cost of inflation. In the present model the only such cost is that associated with price adjustment and the optimal rate of inflation is found as the solution to

$$
\min _{\pi} \mathrm{A}(\pi)+(1-\Psi(\pi)) \mathrm{c}
$$

where the first term is the misallocation term and the second is the costs of price adjustment ( $=$ fraction of firms changing prices times the adjustment cost). It follows that zero inflation is not optimal. The optimal rate of inflation is positive (provided that adjustment costs (c) are not too large, see appendix). The intuition is that low inflation creates nominal rigidities. If inflation is low (zero) firms are less concerned about adjusting prices but this interferes with the need for price adjustment to cope with real shocks so as to ensure an efficient resource allocation.

The misallocation of resources arises due to effects on relative prices. It is often asserted that inflation is costly because it disturbs relative prices and lead to excessive price dispersion. The present analysis shows that this argument overlook the incentives underlying price formation, and that some inflation can be good for the incentives to change nominal prices and thereby reduce relative price dispersion.

Since the model presented here is static it is natural to question whether the results carries over to an explicit dynamic setting. The important point of the present analysis is that inflation induces price adjustment, if there are real shocks necessitating price adjustment it follows that more flexibility in price setting may be beneficial. Explicit dynamic menu cost models also support that inflation is inducive to price adjustment (see the survey in Andersen (1994)). Hence, it is reasonable to conjecture that the basic mechanism analysed here carries over to an explicit dynamic setting.

The argument made here is that inflation interacts with the incentives underlying price adjustment so as to have implications for resource allocation despite the fact that neutrality prevails in the long run. This argument is not directly exploiting the non-neutrality of money implied by nominal price rigidities, that is, the gain included in the comparison made here does not include the short run gain in activity which follows from a (unanticipated) monetary expansion in the presence of nominal rigidities.

The non-neutrality result depends on aggregation over firm specific prices. Despite rigid nominal prices at the firm level it does not necessarily follow that there are aggregate nominal 
rigidities (see e.g. Caplin and Spulber (1987)). However, even though the firm-specific nominal rigidities vanish upon aggregation such that the aggregate price level is proportional to the money stock, it does not follow that the rate of inflation is of no real importance. It is an implication of menu costs that even anticipated nominal changes induce changes in relative prices and thus output variability at the firm level. Changes in the rate of inflation affect the optimal state dependent price of firms and thus in general the average values of output, since the price policy is not symmetric around the optimal relative price. Hence, even though money is neutral, it needs not be super-neutral. This issue has been pursued in a number of papers (Naish (1986), Kuran (1986a,b), Konieczny (1990)), and depending on the properties of the demand, inflation, and cost function and thus the profit function, output may be increasing or decreasing in inflation. Danziger (1988) presents an interesting model where the asymmetry of the profit function implies that the interval for the relative price supported by the firm's price policy is biased downward relative to the optimal relative price in the absence of adjustment costs. In this case inflation reduces the (mean) relative price and thus the market power of firms and thereby it becomes welfare-improving. Notice that this is a completely different argument than the one developed above which focuses on the adjustment to shocks.

Finally, it should be noted that the preceding argument runs counter to the standard argument that inflation has efficiency costs since it tends to create price dispersion inducing resource absorbing search activities on the part of customers. Bénabou $(1998,1992)$ has shown that this is indeed the case but also that one cannot draw any conclusions on the efficiency costs of inflation from this observation since the change in search activity has other implications. First increased search activity tends to reduce the market power of firms and thereby the inefficiency loss caused by imperfect competition. Second, strategic complementarity in price setting implies that the optimal relative price is dependent on the rate of inflation although the direction is in general ambiguous (see above on super neutrality). Hence by introducing search behaviour explicitly in the formulation of demand it follows that inflation has both favourable and unfavourable effects on resource allocation, and it is not possible to make general statements on which dominates. Diamond( 1993) develops a model in which the positive effects dominate for small rates of inflation and the negative dominates for high rates of inflation implying that there is an optimal non-negative rate of inflation.

\section{Empirical evidence}

What is the empirical evidence on the prevalence of nominal rigidities? Empirical analyses of this issue are complicated by two fundamental problems.

First nominal rigidities can mean different things, and it is useful to distinguish between three 
different types of rigidity. Type I rigidity prevails if the nominal wage(or price) is invariant to shocks. This may prevail globally (independently of the size of the shock) or locally (only for "small" shocks). Type II rigidity arises if there is an asymmetry in the adjustment of the nominal wage (price) between downward and upward changes ${ }^{4}$. A special case is when the nominal wage(price) is inflexible in the downward direction but fully flexible in the upward direction. Type III rigidity captures situations where wages (prices) do adjust but by less than implied by frictionless competitive models.

Menu cost models generate rigidities of type I, while standard Keynesian models are often based on a type II downward rigidity of nominal wages, finally models stressing information and synchronization problems usually generate rigidities of type III.

The second major empirical problem is that data on nominal wage and price adjustments have to be compared to some reference values to make it possible to infer whether there are rigidities. Observing unchanged nominal wages and prices does not automatically prove the existence of rigidities as competitive models with fully flexible prices would also predict unchanged prices if the market is not exposed to any shocks. This problem is particularly important as the frequency of unchanged nominal wages and prices naturally is higher in a low inflation environment than in a high inflation environment. To infer that rigidities prevail we need to know something about how behaviour is affected by changes in the rate of inflation.

\subsection{Panel Studies}

The prevalence of nominal rigidities have recently been studied by use of panel data. Table 1 provides an overview of selected recent studies. They all find evidence in support of nominal rigidities in general and downward rigidities in particular. However, the downward rigidity is not absolute in the sense that downward adjustment are never observed, but it is clear that there is a bias in adjustment between the upward and the downward direction. The evidence also clearly indicates that the downward rigidity is most predominant at low rates of inflation.

\footnotetext{
4 See Yates (1998) for a recent and thorough survey of the empirical evidence on downward nominal wage rigidities.
} 


\begin{tabular}{|c|c|c|c|}
\hline Authors & Data & Period & Findings \\
\hline $\begin{array}{l}\text { McLaughlin } \\
\text { (1994) }\end{array}$ & USA:PSID & $1976-86$ & $\begin{array}{l}\text { Real wage cuts are common, and nominal wage costs } \\
\text { are not rare. } \\
\text { The evidence supporting nominal wage rigidity is a } \\
\text { small spike at zero in the nominal wage growth dis- } \\
\text { tribution and incomplete indexing of nominal wage } \\
\text { growth to unanticipated inflation. }\end{array}$ \\
\hline $\begin{array}{l}\text { Card and Hyslop } \\
\text { (1996), }\end{array}$ & USA:CPS and PSID & $1979-93$ & $\begin{array}{l}\text { A reasonable prima facie case for the existence of } \\
\text { nominal wage rigidity for a significant fraction of } \\
\text { workers. } \\
\text { Downward nominal wage rigidities exert a small but } \\
\text { measurable effect on average wage growth, with a } \\
\text { bigger effect in low-inflation years. }\end{array}$ \\
\hline $\begin{array}{l}\text { Goshen and Schweitzer } \\
\text { (1997) }\end{array}$ & $\begin{array}{l}\text { USA: Salary survey data } \\
\text { for Cleveland, Cincinatti } \\
\text { and Pittsburgh }\end{array}$ & $1956-96$ & Evidence of nominal rigidities \\
\hline Kahn (1997) & USA:PSID & $1970-88$ & $\begin{array}{l}\text { Substantial stickiness of nominal wages for wage } \\
\text { earners remaining with the same employer over the } \\
\text { years. }\end{array}$ \\
\hline $\begin{array}{l}\text { Bryan and Cecchetti } \\
\text { (1996) }\end{array}$ & USA: Prices CI & 1967 to 1996 & $\begin{array}{l}\text { Weak negative association between inflation and } \\
\text { skewness in the distribution of relative prices. Some } \\
\text { evidence in support of downward nominal rigidities }\end{array}$ \\
\hline
\end{tabular}


It is noteworthy that empirical support to the assertion that a higher rate of inflation is associated with increased price dispersion is very weak, and that there might in fact be some indication for the reverse association (see Bryan and Cecchetti (1996)).

Survey studies also confirm the role of downward rigidities (see e.g. Bewley (1998) and Agell and Lundborg (1995)). Such studies tend to bring out issues as fairness and motivation as the driving force precluding nominal cuts except in very special situations.

Experimental studies (Fehr and Falk (1997)) also confirm that effort is related to wage levels. As a consequence it is costly to firms to cut wages and this may generate downward rigid wages in markets with incomplete contracts.

\subsection{Time Series Studies}

Countless econometric studies have been made of wage and price formation, both in the form of various Phillips-curve estimates (see eg Hamid, Laxton and Rose (1997) for a recent example and references) and more detailed studies of wage and price formation (see eg Andersen and Hylleberg (1997) for a recent example and references).

The critical issue in the present context is whether nominal rigidities prevail in the short-run. The general finding is that such rigidities are widespread implying that nominal wages and price do not adjust fully to nominal changes in the short run ${ }^{5}$.

A classical question is whether nominal wages or prices display most inflexibility. Spencer (1998) finds that nominal sticky wages have played a more important role than sticky prices in transmitting aggregate demand shocks to real economic activity in the post war US:

\subsection{Shock Decompositions}

As an alternative to consider the process of wage and price formation directly one may indirectly be able to infer something about this process by analysing which type of shocks generate business cycle fluctuations. Most importantly nominal shocks are only capable of generating business cycle shocks provided if there are nominal rigidities in price and wage formation.

Starting with Sims (1980) and Blanchard and Watson(1986) there has been undertaken a number of analyses attempting to decompose the driving forces of business cycle fluctuation into

\footnotetext{
5 Indirect evidence is also provided by eg the PPP puzzle see eg Rogoff (1995).
} 
supply/demand, real/nominal, permanent/ transitory (see e.g. Hartley and Whitt (1997) for a discussion and references). The idea is to impose restrictions of how various type of shocks affects selected variables in the long -run, say, nominal shocks do not have any long run impact on real output. Imposing restrictions of this type makes it possible to infer something about the properties of the shocks generating the business cycle.

This methodology has been applied to data from various countries and periods and the general finding is that nominal shocks also play a role for observed business cycle fluctuations, that is, nominal rigidities must be present.

In short, empirical evidence shows that nominal rigidities matter.

\section{Concluding Remarks}

The presence of nominal rigidities both in the form of exogenous downward rigidities or endogenous rigidities imply that low inflation impairs the adjustment mechanism in decentralized market economies. It is an implications that there are efficiency gains from a positive rate of inflation.

Quantitatively knowledge about wage and price adjustment as well as the occurrence of sector specific shocks is very scant. Accordingly it is difficult to make reliable quantitative assessments of the optimal rate of inflation. However, the gist of the argument suggests that this is a relatively small number, and that adjustment processes work better at an inflation rate of say 2 - 3 percent per year as compared to a zero rate of inflation.

Quantitative assessments of the optimal rate of inflation have recently been made in which the "Shoe-leather" effects of inflation (Lucas (1995)) and the distortions arising from imperfect indexation of the tax system (Feldstein (1996)). It is found that there can be considerable welfare gains in moving to price stability. None of these studies do, however, attempt to include the allocational implications of low inflation in the presence of nominal rigidities. An attempt to quantify the effects hereof is made in Akerlof et al (1996). They calibrate their model to the US economy and find that a movement from 3 percent inflation to price stability would imply an increase in the unemployment rate of at least 1 percentage point. It is still an open question what an analysis including all these aspects of inflation would imply with respect to the optimal rate of inflation. 


\section{Appendix: Welfare Effects of Resource Misallocation}

Note that output and thus consumption of good i can be written

$$
y_{i}=f\left(P_{i} / M\right)
$$

Hence, utility from consumption of this good is given as

$$
\mathrm{u}\left(\mathrm{y}_{\mathrm{i}}\right)=\mathrm{u}\left(\mathrm{f}\left(\mathrm{P}_{\mathrm{i}} / \mathrm{M}\right)\right)=\mathrm{z}\left(\mathrm{P}_{\mathrm{i}} / \mathrm{M}\right) ; \mathrm{z}^{\prime}<0, \mathrm{z}^{\prime \prime}<0
$$

To evaluate the indirect utility at relative prices different from the optimal relative prices, we use the approximation

$$
\begin{aligned}
z\left(\frac{P_{i}}{M}\right)= & z\left(\frac{P_{i}^{*}}{M}\right)+z_{\frac{P_{i}}{M}}^{\prime}\left(\frac{P_{i}^{*}}{M}\right)\left(\frac{P_{i}}{M}-\frac{P_{i}^{*}}{M}\right) \\
& +\frac{1}{2} z_{\frac{P_{i}}{M}}^{\prime \prime}\left(\frac{P_{i}^{*}}{M}\right)\left(\frac{P_{i}}{M}-\frac{P_{i}^{*}}{M}\right)^{2}
\end{aligned}
$$

Assuming a utilitarian welfare criterion and taking the market imperfections imbedded in the market power of firms for given, (ie constrained optimality) implies that the optimum is defined for relative prices, implying

$$
\mathrm{z}_{\frac{\mathrm{P}_{\mathrm{M}}}{\mathrm{M}}}^{\prime}\left(\frac{\mathrm{P}_{\mathrm{i}}^{*}}{\mathbf{M}}\right)=\mathrm{O}
$$

It follows by using a standard $2^{\text {nd }}$ order Taylor approximation that

$$
\mathrm{z}\left(\frac{\mathrm{P}_{\mathrm{i}}}{\mathrm{M}}\right)-\mathrm{z}\left(\frac{\mathrm{P}_{\mathrm{i}}^{*}}{\mathrm{M}}\right)=\frac{1}{2} \mathrm{z}_{\frac{\mathrm{P}_{\mathrm{i}}}{\mathrm{M}}}^{\prime \prime}\left(\frac{\mathrm{P}_{\mathrm{i}}^{*}}{\mathrm{M}}\right)\left(\frac{\mathrm{P}_{\mathrm{i}}}{\mathrm{M}}-\frac{\mathrm{P}_{\mathrm{i}}^{*}}{\mathrm{M}}\right)^{2}
$$

Inserting the price formula, we find

$$
\frac{1}{2} z_{\frac{p_{i}}{M}}^{\prime \prime}\left(\frac{P_{i}^{*}}{M_{i}}\right)\left(\frac{P_{i}}{M}-\frac{P_{i}^{*}}{M}\right)^{2}=\frac{1}{2} z_{P_{i}}^{\prime \prime}\left(\frac{P_{i}^{*}}{M}\right)\left(\frac{m}{1+\pi}-m\left(1+\varepsilon_{i}\right)\right)^{2}
$$

Using the approximation $\frac{1}{1+\mathrm{x}} \sim 1-\mathrm{x}$ for $\mathrm{x}$ small and defining

$$
\chi \equiv-\frac{1}{2} \mathrm{z}_{\frac{\mathrm{P}_{\mathrm{i}}}{\mathrm{M}}}^{\prime \prime}\left(\frac{\mathrm{P}_{\mathrm{i}}^{*}}{\mathrm{M}}\right) \mathrm{m}>0
$$


we get that the welfare costs of the misallocation of good i induced by price rigidity can be written

$$
\chi\left(\pi+\varepsilon_{\mathrm{i}}\right)^{2} \geq 0
$$

Aggregating we find the total costs of misallocation to be

$$
\mathrm{A}(\pi) \equiv \chi \int_{-(\tau-\pi)}^{\tau-\pi}\left(\pi+\varepsilon_{\mathrm{i}}\right) \mathrm{h}\left(\varepsilon_{\mathrm{i}}\right) \mathrm{d} \varepsilon_{\mathrm{i}}
$$

it is assumed that

$$
\mathrm{A}(0)=\chi \int_{-\tau}^{\tau}\left(\varepsilon_{\mathrm{i}}\right)^{2} \mathrm{~h}\left(\varepsilon_{\mathrm{i}}\right) \mathrm{d} \varepsilon_{\mathrm{i}}>\mathrm{c}
$$

that is, there is a trade-off between price adjustment and costs of adjustment.

It follows that

$$
\begin{gathered}
\frac{\partial \mathrm{A}}{\partial \pi}=2 \chi \int_{-(\tau+\pi)}^{\tau-\pi}\left(\pi+\varepsilon_{\mathrm{i}}\right) \mathrm{h}\left(\varepsilon_{\mathrm{i}}\right) \mathrm{d} \varepsilon_{\mathrm{i}}-\chi \tau^{2}[\mathrm{~h}(\tau-\pi)-\mathrm{h}(-(\tau+\pi))] \\
\frac{\partial^{2} \mathrm{~A}}{\partial \pi^{2}}=2 \chi \int_{-(\tau+\pi)}^{\tau-\pi} \mathrm{h}\left(\varepsilon_{\mathrm{i}}\right) \mathrm{d} \varepsilon_{\mathrm{i}}-2 \chi[\mathrm{h}(\tau-\pi)-\mathrm{h}(-(\tau-\pi))] \\
-\chi \tau^{2}\left[-\mathrm{h}^{\prime}(\tau-\pi)+\mathrm{h}^{\prime}(-(\tau-\pi))\right]
\end{gathered}
$$

It is easily verified that there exists a $\pi>0$ for which $\mathrm{A}(\pi)<\mathrm{A}(0)$ by using that

$$
\begin{aligned}
& \left.\frac{\partial \mathrm{A}}{\partial \pi}\right|_{\pi=0}=0 \\
& \left.\frac{\partial^{2} \mathrm{~A}}{\partial \pi^{2}}\right|_{\pi=0}<0
\end{aligned}
$$

Note also that

$$
\mathrm{A}(\pi) \rightarrow 0 \quad \text { for } \pi \rightarrow \infty
$$

The optimal rate of inflation solves

$$
\min _{\pi} \mathrm{A}(\pi)+(1-\psi(\pi)) \mathrm{c}
$$

yielding the first order condition 


$$
\frac{\partial \mathrm{A}}{\partial \pi}=\mathrm{c} \frac{\partial \psi(\pi)}{\partial \pi}
$$

and the second order condition

$$
\frac{\partial^{2} \mathrm{~A}(\pi)}{\partial \pi^{2}}-\mathrm{c} \frac{\partial \psi^{2}(\pi)}{\partial \pi^{2}}>0
$$

Using that

$$
\lim A(\pi)+(1-\psi(\pi)) c= \begin{cases}A(0) & \text { for } \pi \rightarrow 0 \\ c & \text { for } \pi \rightarrow \infty\end{cases}
$$

it follows from $\mathrm{A}(0)>\mathrm{c}$ that there exists a $\pi>0$ for which

$$
\mathrm{A}(\pi)+(1-\psi(\pi)) \mathrm{c}<\mathrm{A}(0)
$$




\section{References}

Agell, J. and P. Lundborg, 1995, Theories of Pay and Unemployment: Survey Evidence from Swedish Manufacturing Firms, Scandinavian Journal of Economics, 97, 223-243.

Akerlof, G.A., W.T. Dickens and G.L. Perry, 1996, The Macroeconomics of Low Inflation, Brookings Papers on Economic Activity, 1-76.

Andersen, T.M., 1995, Price Rigidity- Causes and Implications, Oxford University Press Clarendon (Oxford).

Andersen, T.M. and S. Hylleberg, 1998, Sources of Persistency in the Danish Labour Market, Working Paper, University of Aarhus.

Ball, L. and N.G. Mankiw, 1994, Asymmetric Price Adjustment and Economic Fluctuations, Economic Journal, 104, 247-61.

Bénabou, R., 1988, Search, Price Setting and Inflation, Review of Economic Studies, LV, 353376.

Bénabou, R., 1993,Inflation and Efficiency in Search Markets, Review of Economic Studies, 59, 299-329.

Bewley, T.F., 1998, Why not cut pay?, European Economic Review, Papers and Proceedings, 42, 459-490.

Blanchard, O. and M.W. Watson, 1986, Are Business Cycles all Alike? in R.J. Gordon, ed., The American Business Cycle, Continuity and Change, University of Chicago Press, 123-179.

Bryan, M.F. and S.G. Cecchetti, 1996, Inflation and the Distribution of Price Changes, NBER WP 5793.

Caplin, A. and D.F. Spulber, 1987, Menu Costs and the Neutrality of Money, Quarterly Journal of Economics, 106,683-799.

Card, D. and D Hyslop, 1996, Does Inflation "Grease the Wheels of the Labor Market ", NBER WP 5538. 
Chadka, J.S., A.G. Haldane and N.G. Janssen, 1998, Shoe-leather Costs Reconsidered, Economic Journal, 108, 363-382.

Danziger, L., 1988, Costs of Price Adjustment and the Welfare Economics of Inflation and Disinflation. American Economic Review, 78, 633-646.

Diamond, P, 1992, Search, Sticky Prices, and Inflation, Review of Economic Studies, 60, 53-68

Edey, M., 199x, Costs and Benefits of Moving from Low Inflation to Price Stability, OECD Economic Studies, 23, 109-103.

Feldstein, M., 1996, The Costs and Benefits of Going from Low Inflation to Price Stability, NBER Working Paper 5469.

Fehr, E. and A. Falk, 1997, Wage Rigidity in a Competitive Incomplete Contract Market - An Experimental Investigation, Journal of Political Economy (to appear).

Groshen, E.L. and M. E Schweitzer, 1997, Identifying Inflation's Grease and Sand Effects in the Labor Market, Federal Reserve Bank of Cleveland, Discussion Paper 97-05.

Gylfason, T.and T. Herbertsson, 1998, Inflation and Growh, CEPR Discussion Paper.

Hamid, F., D. Laxton and D. Rose,. 1997, Inflation and Unemployment in Europe and North America: Asymmetry versus Hysteresis, IMF Working Paper.

Hartley P.R. and J.A. Whitt, Jr., 1997, Macroeconomic Fluctuations in Europe: Demand or Supply, Permanent or Temporary?, Federal Reserve Bank of Atlanta, WP 97-14.

Holden, S., 1994, Wage Bargaining and Nominal Rigidities, European Economic Review, 38,

Holden, S., 1997, Wage Bargaining, Holdout and Information, Oxford Economic Papers, 49.

Kahn, S., 1997, Evidence of Nominal Wage Stickiness from Microdata, American Economic Review, 87, 993-10008.

Konieczny, J., 1990, Inflation, Output and Labour Productivity when Prices are Changed Infrequently, Economica, 57, 201-18. 
Kuran, T., 1986(a), Anticipated Inflation and Aggregate Employment: The Case of Costly Price Adjustment, Economic Inquiry, XXIV, 293-311.

Kuran, T., 1986(b), Price Adjustment Costs, Anticipated Inflation, and Output, Quarterly Journal of Economics, 407-418.

Lilien, D.M., (1982), Sectoral Shifts and Cyclical Unemployment, Journal of Political Economy, 90, 777-793.

Naish, H.F., 1986, Price Adjustment Costs and the Output-Inflation Trade-off, Economica, 53, 219-30.

Rogoff, K., 1995, The Purchasing Power Parity Puzzle, Journal of Economic Literature, XXXIV, 647-668.

Sims, C., 1980, Macroeconomics and Reality, Econometrica, 1-48.

Spencer, D.E., The Relative Stickiness of Wages and Prices, Economic Inquiry, XXXVI, 120137.

Tobin, J., 1972, Inflation and Unemployment, American Economic Review, LXII, 1-18.

Tsiddon, D., 1991, On the Stubbornness of Sticky Prices, International Economic Review, 32, 69-75.

Yates, A., 1998, Downward Nominal Rigidity and Monetary Policy, Bank of England, Working Paper Series no. 98. 